\title{
Social Contact and Health among Chinese Older Adults in China
}

\author{
Andi Chen \\ Beijing Middle School, China
}

\begin{abstract}
Social contact is important for successful aging. Numerous studies have established that close connections to and participation in social groups and communities provide support, increase a sense of belonging and access to information that can be key for physical and mental health. Compared with numerous findings on social engagement and health in Western world, empirical evidence in the research area from non-Western settings is limited. Using a nationwide representative sample of older adults in China, this study continues efforts along this line by studying how social contact influence mental and physical health among Chinese older adults. The findings suggest that increasing social contact has a positive relationship with physical and mental health among Chinese elders.
\end{abstract}

Keywords: social contact, health, older adults, aging

\section{Background}

The past few decades have witnessed a phenomenal shift with respect to population ageing. The recent fall of fertility toward and below replacement fertility and the improvement in life expectancy, combined with the past changes in death and birth rates have caused, and will cause, a significant increase in the proportion of older people (Bloom, Canning \& Fink, 2010). In 2019, there were 703 million persons aged 65 years or over in the global population. UN estimation projected that this number is going to double to 1.5 billion in 2050 (United Nation, 2019). China, the most populous country with roughly one-fifth of the world's population, is ageing at an accelerated pace that surpasses many of the other advanced ageing societies (Chen \& Chan, 2011). The growth in the senior population in China poses challenges to not only Chinese society but also the world for its overall population size. Existing institutions are facing increasing burdens since senior citizens have growing health care needs, and may be more dependent on the support of others (Muramatsu, 2003). Moreover, the individuals are potentially more vulnerable to socio-economic changes and changes in the environment, as they tend to be more cognitively, psychologically, and physically reliant on the community context than younger adults (Robert \& Li, 2001). The health of Chinese elderly is therefore a central issue both for researchers and policy-makers.

Social contact is important for successful aging (Bath and Deeg, 2005). Numerous studies have established that close connections to and participation in social groups and communities provide support, increase a sense of belonging and access to information that can be key for physical and mental health (Berkman et al., 2000). 


\section{4th International Conference On Research In HUMANITIES \& SOCIAL SCIENCES}

One of the pathways that greater social contact linked to better health is via psychological process (Kawachi \& Berkman, 2001). For example, Glass et al. (2006) revealed that social engagement predicted lower levels of depression over time among a large sample of community-dwelling elders (Sani et al., 2012). Lin, Dean and Ensel (2013) attempt to conceptualize social support and assess the reliability and validity of its various measures. They then evaluate the ability of social support, along with stressors, to explain psychiatric symptoms. The result suggested that support measures clearly exert strong effects on depression and other psychiatric symptoms.

The other major pathway that social contact influences health is via health behaviours. Social contact is health-promoting because it facilitates healthier behaviours such as physical activities, health diet, reduced smoking and greater adherence to medical regimens (Berkman et al., 2000). The impact can happen in a direct channel via health-related informational support or via indirect channel such as life meaning (Uchino, 2006). For example, Hanson et al. (1990) have reported that social support is related to smoking cessation, especially among men.

Compared with numerous findings on social contact and health in Western world, empirical evidence in the research area from non-Western settings is limited. Using a nationwide representative sample of older adults in China, the aim of this study is to continue efforts along this line by studying how social contact influence mental and physical health among Chinese older adults.

\section{Research Question:}

1. How does social support influence mental health among Chinese older adults?

2. How does social support influence physical health among Chinese older adults?

\section{Methods}

The large-scale survey on the health of elderly was rarely available in China before the $21 \mathrm{st}$ century. The main data set of this dissertation is the 2015 national baseline survey of the Chinese Health and Retirement Longitudinal Study (CHARLS), which is an on-going collaborative project of the University of Southern California, University of Oxford, and Peking University. The survey is designed based on an American model: the Health and Retirement Study (HRS) of the University of Michigan, and is related to other ageing surveys such as the English Longitudinal Study of Aging (ELSA) and the Survey of Health, Aging and Retirement in Europe (SHARE). CHARLS is a longitudinal panel study designed to provide a wide range of information from socio-economic status and social support to health conditions from a high quality nationally representative sample of Chinese residents age 45 and above. The total sample of the baseline national wave comprises individuals across 28 provinces in China (Figure $1)$. 


\section{iorhs}

\section{4th International Conference On Research In}

HUMANITIES \& SOCIAL SCIENCES

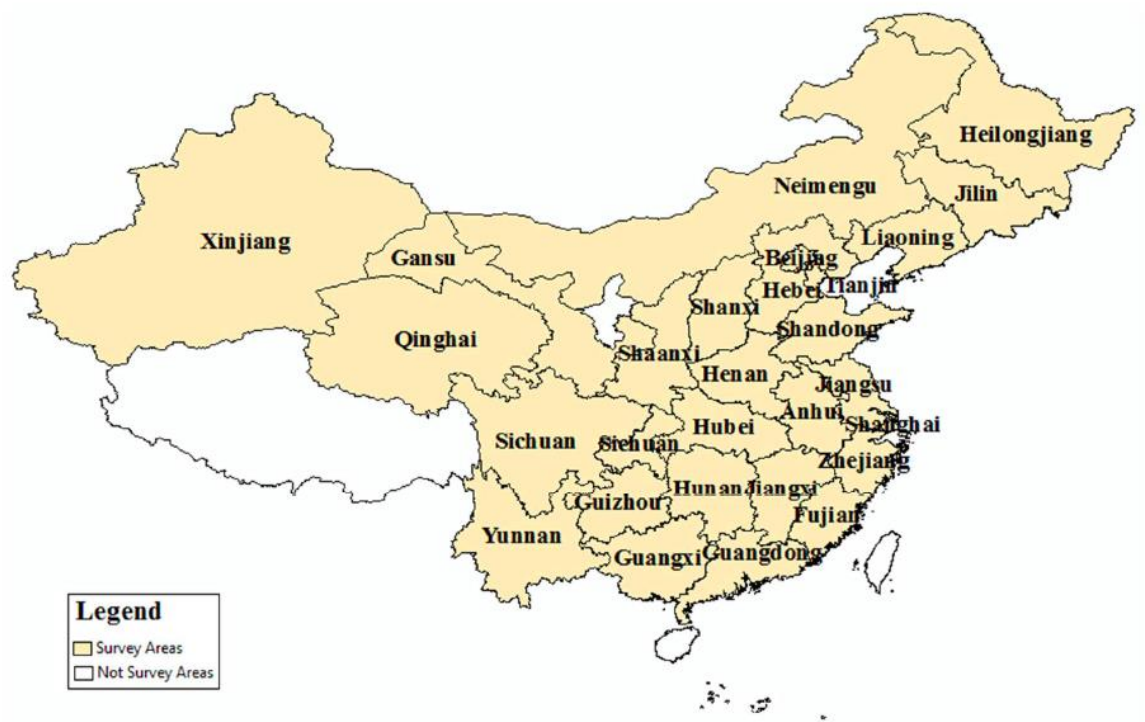

Source: Evandrou, M., Falkingham, J., Feng, Z. F., \& Vlachantoni, A. Individual and province inequalities in health among older people in China: evidence and policy implications [PowerPoint slides]. Retrieved from: https://www.oal.cuhk.edu.hk/files/wun/2b._Southampton___Maria_Athina.pdf

The CHARLS national baseline data has some major advantages over existing Chinese data that has been used to analyse the relationship between income inequality and health. Despite the CHARLS dataset's public availability, CHARLS data set is the ideal survey to test hypotheses that refer to the older population across China. Moreover, the CHARLS data set has relatively high external validity because the sample is large and heterogeneous from both urban and rural areas across 28 provinces.

The key independent variable in this study is social engagement. In Charls, information about social engagement is obtained mainly through the question "How often do you see children/parents-in-law/siblings/grandchildren/friends?" for which there are options: 1. Almost every day, 2. 2-3 times a week, 3. Once a week, 4. Every two weeks, 5. Once a month, 6. Once every three months, 7. Once every six months, 8. Once a year, 9. Almost never, 10. Other

The key independent variable in this study is mental and physical health. Mental health is measured by the question "How would you rate your memory at the present time? for which there are options: 1. Excellent, 2. Very good, 3. Good, 4. Fair, 5. Poor

Physical health is measured by "Would you say your health is excellent, very good, good, fair, or poor?" for which there are options: 1. Excellent, 2. Very good, 3. Good, 4. Fair,

5. Poor

Ordinary least squares models will be used for data analyses. 


\title{
iorhs
}

\section{4th International Conference On Research In HUMANITIES \& SOCIAL SCIENCES}

\begin{abstract}
Results
Using data from CHARLS wave 4, Table 1 reports descriptive statistics of self-rated health, mental health and predictors among Chinese older adults by area of residence and gender. Among the total sample $(\mathrm{N}=18,140)$, people living in urban area has better self-rated health $($ Mean $=3.71$, Std. $=0.95)$ than people from rural area $($ Mean $=3.86$, Std. $=0.94)$. The difference in self-rated health between the two subgroup is significant. Male report better self-rated health $($ Mean $=3.71$, Std. $=0.97)$ than female $($ Mean $=3.88$, Std. $=0.92)$. Urban residents enjoy a lower risk of mental health problem $($ Mean $=1.72$, Std. $=1.02)$ compared to their counterparts in the rural area $($ Mean $=1.92$, Std. $=1.11)$. Males suffer less from mental health problem $($ Mean $=1.68$, Std. $=0.99)$ than female $($ Mean $=1.99$, Std. $=1.13)$. In rural area, $90 \%$ of the sample have social contact each week. The proportion is higher in urban area $(95 \%)$. Female have slightly more social contact (92\%) than males (91\%). The age distribution in our sample is balanced among rural and urban area. Males are slightly older than female respondents. As expected, rural residents' educational attainment $($ Mean $=1.07$, Std. $=0.26)$ is lower than urban residents $($ Mean $=1.24$, Std. $=0.53)$. Males have higher educational attainment $($ Mean $=1.18$, Std. $=0.46)$ than female $($ Mean $=1.09$, Std. $=0.33)$. The difference between urban and rural areas, and between gender are all statistically significant, except for age difference in rural and urban area.
\end{abstract}

Social contact is associated with better self-rated health. Social contact is associated with 0.12 (std.err. $=0.03$ ) decrease in self-rated health. Model 1 with social contact as the sole predictor explains only $0.1 \%$ of the total variance of self-rated health. Model 2 controls age, gender, area of residence, and educational attainment. The coefficient of contact decreased from -0.12 to 0.08 (std.err. $=0.03$ ). Even after adjusting for the control variables, social contact still has an independent effect on self-rated health. Adding control variables increase the explanatory power from $0.1 \%$ to $3 \%$.

Social contact is associated with less depressive symptoms (coefficient $=-0.13$, std.err $=0.03$, Model 3). After adjusting for control variables in Model 4, the size of the coefficient decreased to -0.1 (std.err. $=0.03$ ). The effect is still statistically significant. Adjusting for covariates largely increased the explanatory power from Model 3 to Model 4.

\section{Discussion}

Aging poses a significant challenge to individual and public health. Promoting health and wellbeing to improve successful aging is a topic of importance in contemporary China. Using detailed longitudinal data from the CHARLS conducted in 2015, we applied multivariate linear regression models to gain more insight into the association between social contact and health among older adults. We found that social contact is associated with both physical and mental health. The effects from social contact are independent and significant even after controlling for potential confounders. We also find that older adults in urban area have better health, both in terms of physical and mental health, and more social contact compared to adults residing in the rural area.

Our finding suggests that policy interventions to diminish the gap between rural and urban areas may maintain and improve self-rated health and mental health among the elderly. The 


\section{iorhs}

\section{4th International Conference On Research In HUMANITIES \& SOCIAL SCIENCES}

government may establish community center to facilitate an elderly-friendly environment, especially in the rural area, to increase social contact.

This study enriches and expands on previous Western-focused research and contributes to the literature by studying China, a country that is experiencing accelerated aging. We measure both physical and mental health, providing a more comprehensive understanding. Though the work provides evidence for association between social contact and health among older adults, the study suffers from several limitations. First, we didn't include income level which may be associated with both social contact and health. However, we adjusted for educational attainment as the measure of socioeconomic status, which is highly correlated with income level. Second, we used one wave from the dataset and conducted a cross-sectional analysis. Future analysis using longitudinal dataset analyzing the changing pattern of elderly health will bring more insight to understanding successful ageing.

\section{Conclusion}

China is currently experiencing rapid aging, and it has the largest elderly population in the world. Identifying the predictors that affect health among older adults is crucial given the speed of ageing. Among the fundamental causes of health, social contact emerges as an more and more important concept. In this study, we therefore analyze 1). How does social contact influence mental health among Chinese older adults? 2). How does social support influence physical health among Chinese older adults? Using a representative Chinese dataset, our findings suggest that increasing social contact has a positive impact on physical and mental health among Chinese older people and is important for successful aging. Policy interventions that aims to increase social contact, especially for rural residents may improve elderly health in China. 


\section{icrhs}

\section{4th International Conference On Research In}

HUMANITIES \& SOCIAL SCIENCES

Table 1. Descriptive statistics of self-rated health, depression and predictors among Chinese older adults by area of residence and gender (CHALRS)

\begin{tabular}{|c|c|c|c|c|c|c|c|c|c|}
\hline \multirow[t]{2}{*}{ Variable } & \multirow[t]{2}{*}{ Definition } & \multirow{2}{*}{$\begin{array}{l}\text { All } \\
\text { Mean/\% } \\
\text { (SD) }\end{array}$} & \multicolumn{2}{|c|}{$\begin{array}{l}\text { Area of Residence } \\
\text { Mean/\% (SD) }\end{array}$} & \multicolumn{2}{|c|}{$\begin{array}{c}\text { Gender } \\
\text { Mean/\% (SD) }\end{array}$} & \multirow[t]{2}{*}{ Min } & \multirow[t]{2}{*}{ Max } & \multirow[t]{2}{*}{ Obs. } \\
\hline & & & Rural & Urban & Female & Male & & & \\
\hline $\begin{array}{l}\text { Self-rated } \\
\text { health }\end{array}$ & $\begin{array}{l}\text { Self-rated: } \\
\text { Excellent }=1, \\
\text { Very good }=2, \\
\text { Good }=3, \\
\text { Fair }=4, \\
\text { Poor }=5\end{array}$ & $\begin{array}{l}3.8 \\
(0.94)\end{array}$ & $\begin{array}{l}3.86 \\
(0.94)\end{array}$ & $\begin{array}{l}3.71^{* * *} \\
(0.95)\end{array}$ & $\begin{array}{l}3.88 \\
(0.92)\end{array}$ & $\begin{array}{l}3.71^{* * *} \\
(0.97)\end{array}$ & 1 & 5 & 18,140 \\
\hline $\begin{array}{l}\text { Mental } \\
\text { health }\end{array}$ & $\begin{array}{l}\text { Rarely or none of } \\
\text { the time }<1 \text { day }= \\
1, \\
\text { Some or a little of } \\
\text { the time } 1-2 \text { days } \\
=2 \text {, Occasionally } \\
\text { or a moderate } \\
\text { amount of }=3 \text {, } \\
\text { Most or all of the } \\
\text { time } 5-7 \text { days }=4\end{array}$ & $\begin{array}{l}1.84 \\
(1.08)\end{array}$ & $\begin{array}{l}1.92 \\
(1.11)\end{array}$ & $\begin{array}{l}1.72^{* * *} \\
(1.02)\end{array}$ & $\begin{array}{l}1.99 \\
(1.13)\end{array}$ & $\begin{array}{l}1.68^{* * *} \\
(0.99)\end{array}$ & 1 & 4 & 18,140 \\
\hline $\begin{array}{l}\text { Social con- } \\
\text { tact }\end{array}$ & $0=$ no, $1=$ yes & 0.92 & 0.90 & $0.95^{* * *}$ & 0.92 & $0.91^{*}$ & 0 & 1 & 18,140 \\
\hline Age & $\begin{array}{l}\text { Continuous varia- } \\
\text { ble }\end{array}$ & $\begin{array}{l}60.95 \\
(10.70)\end{array}$ & $\begin{array}{l}60.00 \\
(9.70)\end{array}$ & $\begin{array}{l}59.94 \\
(9.84)\end{array}$ & $\begin{array}{l}59.67 \\
(9.73)\end{array}$ & $\begin{array}{l}60.30^{* * * *} \\
(9.77)\end{array}$ & 45 & 115 & 18,140 \\
\hline Gender & $1=$ female, $0=$ male & 0.51 & 0.51 & $0.52^{*}$ & & & 0 & 1 & 18,140 \\
\hline Rural & $1=$ rural, $0=$ urban & & & & 0.60 & $0.61^{*}$ & 0 & 1 & 18,140 \\
\hline Education & $\begin{array}{l}1=\text { Less than lower } \\
\text { secondary , } 2=\text { up- } \\
\text { per secondary \& } \\
\text { vocational train- } \\
\text { ing , } 3=\text { tertiary }\end{array}$ & $\begin{array}{l}1.2 \\
(0.4)\end{array}$ & $\begin{array}{l}1.07 \\
(0.26)\end{array}$ & $\begin{array}{l}1.24^{* * *} \\
(0.53)\end{array}$ & $\begin{array}{l}1.09 \\
(0.33)\end{array}$ & $\begin{array}{l}1.18^{* * *} \\
(0.46)\end{array}$ & 1 & 3 & 18,140 \\
\hline
\end{tabular}

Significance level: ${ }^{*} \mathrm{p}<0.5,{ }^{* *} \mathrm{p}<0.01,{ }^{* * *} \mathrm{p}<0.001$

Standard deviations are in parentheses. 


\section{iorhs}

\section{4th International Conference On Research In}

HUMANITIES \& SOCIAL SCIENCES

Table 2. Estimates of the effect of social contact on self-rated health and mental health of the older adults in China

\begin{tabular}{llccc}
\hline & \multicolumn{2}{c}{ Self-rated health } & \multicolumn{2}{c}{ Mental health } \\
\cline { 2 - 5 } & \multicolumn{1}{c}{ Model1 } & \multicolumn{1}{c}{ Model2 } & Model3 & \multicolumn{1}{c}{ Model 4} \\
\hline Contact & $-0.12^{* * *}(0.03)$ & $-0.08^{* *}(0.03)$ & $-0.13^{* * *}(0.03)$ & $-0.10^{* * * *}(0.03)$ \\
Age & & $0.01^{* * *}(0.001)$ & & $0.003^{* * *}(0.0008)$ \\
Gender & & $0.16^{* * *}(0.01)$ & & $0.30^{* * * *}(0.02)$ \\
Rural & & $0.13^{* * *}(0.01)$ & $0.18(0.17)$ \\
Education & & $-0.12^{* * *}(0.02)$ & & $-0.14^{* * *}(0.20)$ \\
Constant & $3.91^{* * *}(0.02)$ & $3.18^{* * *}(0.06)$ & $1.96^{* * *}(0.03)$ & $1.63^{* * *}(0.07)$ \\
Observations & 18,140 & 18,140 & 18,140 & 18,140 \\
Adjusted $\mathrm{R}^{2}$ & 0.001 & 0.03 & 0.001 & 0.03 \\
\hline
\end{tabular}

Note: standard errors are reported in parentheses. Significance levels: ${ }^{*} \mathrm{p}<0.5,{ }^{* *} \mathrm{p}<0.01,{ }^{* * *} \mathrm{p}<0.001$. 


\section{icrhs}

\section{4th International Conference On Research In}

HUMANITIES \& SOCIAL SCIENCES

\section{Reference:}

Bath, P. A., \& Deeg, D. (2005). Social engagement and health outcomes among older people: introduction to a special section. European Journal of Ageing, 2(1), 24-30.

Berkman, L. F., Glass, T., Brissette, I., \& Seeman, T. E. (2000). From social integration to health: Durkheim in the new millennium. Social science \& medicine, 51(6), 843-857.

Bloom, D. E., Canning, D., \& Fink, G. (2010). Implications of population ageing for economic growth. Oxford review of economic policy, 26(4), 583-612.

Chen, K., \& Chan, A. H. (2011). The ageing population of China and a review of gerontechnology. Gerontechnology, 10(2), 63-71.

Hanson, B. S., Isacsson, S. O., Janzon, L., \& Lindell, S. E. (1990). Social support and quitting smoking for good. Is there an association? Results from the population study,"Men born in 1914," Malmö, Sweden. Addictive Behaviors, 15(3), 221-233.

Kawachi, I. , \& Berkman, L. F. . (2001). Social ties and mental health. Journal of Urban Health, $78(3), 458-467$.

Lin, N., Dean, A., \& Ensel, W. M. (Eds.). (2013). Social support, life events, and depression. Academic Press.

Muramatsu, N. (2003). County- level income inequality and depression among older Americans. Health services research, 38(6p2), 1863-1884.

Robert, S. A., \& Li, L. W. (2001). Age variation in the relationship between community socioeconomic status and adult health. Research on aging, 23(2), 234-259.

Sani, F. , Herrera, M. , Wakefield, J. R. H. , Boroch, O. , \& Gulyas, C. . (2012). Comparing social contact and group identification as predictors of mental health. British Journal of Social Psychology, 51(4).

Sieber, \& Joan, E. . (1974). Effects of decision importance on ability to generate warranted subjective uncertainty. Journal of Personality \& Social Psychology, 30(5), 688-694.

Uchino, B. N. (2006). Social support and health: a review of physiological processes potentially underlying links to disease outcomes. Journal of behavioral medicine, 29(4), 377387.

United Nations, Department of Economic and Social Affairs, Population Division (2019). World Population Ageing 2019: Highlights (ST/ESA/SER.A/430). 